\title{
UPACARA PEWINTENAN JRO PASEK DESA PAKRAMAN LES-PENUKTUKAN: KAJIAN LINGUISTIK BUDAYA
}

\author{
Ketut Riana ${ }^{1}$, Putu Evi Wahyu Citrawati ${ }^{2}$, I.G.A Istri Aryani ${ }^{3}$, dan Fransiska Dewi Setiowati $\mathrm{S}^{4}$ \\ Fakultas Ilmu Budaya, Universitas Udayana \\ eviwahyu78@gmail.com
}

Abstrak - Upacara mewinten atau upanaya merupakan salah satu upacara manusa yadnya. Secara lahiriah mewinten berarti pembersihan diri dari kotoran yang melekat pada diri, dengan menggunakan sarana air dan beraneka ragam bunga. Upacara pewintenan Jro Pasek yang ada di Desa Pakraman Les-Penuktukan merupakan salah satu upacara yang ada di masyarakat Bali Aga/Bali Kuno.

Upacara ini bertujuan untuk membersihkan seseorang yang akan menjadi penghulu adat, yang bertugas untuk memimpin upacara dan mempimpin masyarakat secara adat. Upacara ini diawali dengan pembersihan di rumah Jro Pasek yang terpilih, kemudian siang harinya calon Jro Pasek datang ke Pura Bale Agung yang diiringi oleh krama desa adat, untuk melakukan pewintenan di Pura Bale Agung. Upacara pewintenan ini dipimpin oleh Jro Mangku tertua dan tertinggi kedudukannya di Desa Adat Les-Penuktukan, yaitu Jro Mangku Puseh. Setelah itu, Jro Pasek mekemit di Pura selama tiga hari. Setelah tiga hari diadakan upacara mancangkarma ke segara.

Penelitian ini merupakan penelitian yang bersifat lapangan. Penelitian lapangan biasanya dibantu dengan beberapa teknik untuk menjaring data, seperti teknik wawancara dan dibantu dengan teknik catat. Semua data yang direkam kemudian ditranskripsikan dengan menggunakan kartu data. Teknik penyajian hasil penelitian ini menggunakan metode formal dan informal. Metode formal, yaitu berupa penyajian hasil analisis data dengan perumusan lambang-lambang, tabeltabel, dan sebagainya. Metode informal adalah penyajian kaidah dengan rumusan kata-kata biasa.

Kata Kunci: pewintenan, Jro Pasek, penghulu adat.

\begin{abstract}
Mewinten or Upanaya is one of the Manusa Yadnya ceremonies. Physically, mewinten berate is a self purification conducted by using water and flowers. Jro Pasek's pewintenan ceremony at Pakraman Village Les-Penuktukan is one of the Bali Aga or Bali Kuna society's ceremonies. It aims to purify the personal to be headmen of the ritual ceremony. In custom, he has the duty to lead the ceremony and society. Initially, the ceremony is purified at the personal selected of Jro Pasek's house. And then, during the afternoon the selected Jro Pasek enter Bale Agung temple accompanied by the village custom to conduct pewintenan ceremony. This ceremony leads by the eldest and highest position as Jro Mangku at Les-Penuktukan, Jro
\end{abstract}


LINGUISTIKA, MARET 2019

p-ISSN: 0854-9613

Vol. 26. No. 1

Mangku Puseh. Moreover, Jro Pasek will be staying up late (mekemit) at the temple for 3 days. After 3 days it will be continued with mancangkarma ceremony to the beach.

This study is a field research assisted with some techniques to collect datas such as: interview and note taking. All recorded data then being transcript by data cards. Formal and informal methods are the techniques used for the discussion of result analysis. Formal method consists of with symbols, table, etc., meanwhile informal method is using words in explanation.

Keywords: pewintenan, Jro Pasek, penghulu adat 


\section{PENDAHULUAN}

Mewinten merupakan salah satu upacara penyucian diri dan tergolong ke dalam upacara manusa yadnya. Kata mewinten berasal dari kata "winten" yang berarti intan. Jika dilihat dari asal katanya, berarti bersih dan suci. Secara lahiriah mewinten bertujuan untuk membersihkan diri dari kekotoran yang melekat pada diri seseorang dengan menggunakan sarana air dan bunga harum, sedangkan secara batiniah bertujuan untuk memohon penyucian diri kepada Hyang Widhi Wasa/Tuhan Yang Maha Esa agar diberikan waranugraha berupa tuntunan, bimbingan dalam mempelajari ilmu pengetahuan yang bersifat suci, seperti kesusilaan, Weda, susastra, dan lain-lain.

Landasan sastra agama upacara mewinten dijumpai dalam berbagai pustaka lontar, seperti lontar Tutur Pemangku yang berisi tentang dharma pewintenan. Tutur pewintenan berisi tentang tata cara pewintenan yang paling kecil dengan upacara dan upakaranya. Dalam lontar Janma Prakerti diutarakan tingkatan-tingkatan upacara pewintenan. Berdasarkan pustaka lontar di atas diketahui beberapa jenis pewintenan, antara lain (1) pewintenan sastra/saraswati, (2) pawintenan pemangku, (3) pawintenan dalang, (4) pawintenan tukang, (5) pawintenan dasaran, dan (6) pawintenan mahawisesa atau pewintenan pengurus adat.

Pawintenan mahawisesa memiliki tujuan khusus untuk menyucikan diri secara lahir batin pengurus desa adat atau bendesa adat. Tujuannya agar dalam pengabdiannya dapat mengemban tugas yang sesuai dengan ajaran agama Hindu dan aturan desa adat setempat.

Secara geografis, masyarakat Bali dibagi menjadi dua wilayah permukiman, yaitu wilayah Bali Daratan dengan dialek Bali Dataran (DBA) serta wilayah Bali Pegunungan yang dikenal dengan wilayah
Bali Aga dengan Dialek Bali Aga (Bawa, 1983:394). Dialek Bali Dataran digunakan oleh masyarakat di wilayah dataran Pulau Bali seperti selatan atau daerah pesisir Pulau Bali, sedangkan dialek Bali Aga digunakan oleh masyarakat Bali yang mendiami wilayah pegunungan.

Dialek Bali Aga dikelompokkan ke dalam tiga daerah permukiman (Bawa, 1983:394). Pertama, DBA yang digunakan oleh kelompok masyarakat timur Pulau Bali yang meliputi wilayah Kabupaten Karangasem (Tenganan), sejumlah wilayah di Kecamatan Kintamani Bangli (sekitar Danau Batur), DBA yang digunakan oleh masyarakat Nusa Penida di Kabupaten Klungkung, dan sebagian wilayah Buleleng Timur. Gabungan masyarakat penutur DBA di wilayah Kecamatan Kintamani dan wilayah Buleleng timur disebut dengan masyarakat gebog domas. Kedua, DBA yang digunakan oleh masyarakat yang berada di wilayah pegunungan Badung Utara, seperti wilayah Pelaga, Tihingan, dan Seminyak. Ketiga, DBA yang digunakan oleh masyarakat bagian barat Pulau Bali, seperti Kabupaten Tabanan, yang meliputi wilayah Kecamatan Pupuan (Pujungan), wilayah Kecamatan Penebel ( Desa Wongaya), dan sebagian wilayah Buleleng Barat, seperti Desa Bantiran, Desa Sepang, Padawa yang berada di Kecamatan Busungbiu (Riana, 1995:3).

Desa Les-Penuktukan (yang selanjutnya disebut Desa Pakraman LesPenuktukan) merupakan salah satu desa Bali Aga yang terdapat di wilayah Bali Utara. Sebagai salah satu desa Bali Aga, Desa Pakraman Les-Penuktukan memiliki bahasa dan dialek tersendiri yang berbeda dengan dialek bahasa Bali Dataran.

Desa Les secara administratif merupakan bagian dari Kecamatan Tejakula yang memiliki luas wilayah kurang lebih $97,86 \mathrm{~km}^{2}$ dan terletak di sisi timur Kabupaten Buleleng. Kecamatan Tejakula merupakan kecamatan paling timur di 
Kabupaten Buleleng. Kecamatan ini memiliki garis pantai yang terpanjang kedua di Kabupaten Buleleng. Topografi Kecamatan Tejakula adalah dataran rendah dengan suhu rata-rata $28^{\circ} \mathrm{C}$. Kecamatan Tejakula terdiri atas sepuluh desa. Salah satu desa yang ada di Kecamatan Tekajula adalah Desa Les.

Asal mula nama Desa Les dapat dijelaskan secara ringkas. Nama Les berasal dari kata ngenes yang berarti melikes atau pergi dari suatu tempat ke tempat yang baru sambil bersembunyi. Akan tetapi, kata ngenes ditulis dengan huruf Bali. Huruf 'nge dan melele oleh orang-orang yang paham pasang aksara sastra Bali menjadi nge melele/me megantungan ne yang metengenan se dibaca menjadi Les dan sampai saat ini tetap dibaca Les.

Desa Les terletak di sebelah timur Desa Tejakula, yang sekaligus sebagai ibu kota kecamatan. Batas desa Les adalah di sebalah barat berbatasan dengan Desa Tejakula, sebelah timur berbatasan dengan Desa Penuktukan, sebelah utara Laut Bali, dan di sebelah selatan berbatasan dengan hutan Bangli. Luas wilayah Desa Les kurang lebih 769 hektare, termasuk di dalamnya adalah hutan, tegalan, dan ladang penduduk. Desa Les terdiri atas sembilan dusun, yaitu dusun, yakni (1) Dusun Kanginan, (2) Dusun Kawanan, (3) Dusun Butiyang,

Panjingan, (5) Tegallinggah, (6) Selonding, (7) Tubuh, (8) Lempedu, dan (9) Dusun Penyumbahan. Mata pencaharian penduduk Desa Les beragam, ada sebagai petani, nelayan, pekerja bangunan, pedagang, pengusaha, dan PNS. Namun, sebagian besar masyarakat bekerja di sektor nonformal.

Istilah Jro Pasek mungkin terdengar asing bagi masyarakat Hindu terutama masyarakat di luar Bali Aga. Jro Pasek adalah seorang bendesa adat yang ada dalam struktur organisasi masyarakat adat Bali Kuno di Desa Les-Penuktukan. Jro Pasek memiliki tugas-tugas untuk memimpin adat secara adat di Desa Adat Les-Penuktukan yang terdiri atas 28 kraman atau yang dikenal dengan pengulu ululikur. Tugas utama Jro Pasek adalah memimpin semua upacara, baik di desa adat maupun desa dinas.

\section{TEORI \& METODOLOGI}

Bahan kajian ini bersumber dari data lisan dan rekaman video pada saat pelaksanaan upacara pawintenan Jro Pasek. Data dikumpulkan melalui metode observasi langsung dan menggunakan teknik wawancara (Hadi, 1990:136).

Ada banyak teori dari berbagai macam pendapat tentang linguistik kebudayaan. Pada dasarnya linguistik kebudayaan atau linguistik budaya merupakan bidang interdisipliner (lintas bidang) yang mempelajari hubungan antara bahasa dan kebudayaan di dalam suatu komunitas masyarakarat. Koentjaraningrat (1983:182) mengatakan bahwa bahasa merupakan bagian dari sebuah kebudayaan. Sebaliknya, kebudayaan diwariskan secara turun-temurun melalui media bahasa, dengan kata lain bahwa budaya berkembang melalui media massa. Ada beberapa istilah yang sering digunakan untuk menyebutkan linguistik kebudayaan. Foley (1997:1) mengatakan linguistik kebudayaan sama dengan anthropological linguistic atau linguistik antropologi. Hal ini disebabkan oleh bahasa dikaji dari perspektif antropologi untuk menemukan dan menentukan makna di balik penggunaan bahasa. Namun, jauh sebelumnya ahli bangsa Eropa telah memperkenalkan istilah ethnolinguistic, yang terkenal pada tahun 1940-an. Pada dasarnya semua pendapat ahli tersebut mengatakan bahwa linguistik kebudayaan ataupun linguistik antropologi adalah perpaduan antara dua bidang interdisipliner antara bahasa dan kebudayaan. Cakupan studi linguistik kebudayaan, antara lain menelaah (1) hubungan intrinsik antara bahasa dan 
budaya dan bahasa dipandang sebagai suatu fenomena budaya, (2) memberikan perhatian pada fungsi yang diperankan antara bahasa dan bahasa itu sendiri dianggap sebagai sebuah institusi budaya, (3) kajiannya berhubungan dengan istilah language in cultural atau language and cultural sehingga ada makna budaya di balik bahasa, (4) studi yang menjangkau semua aspek (tujuh aspek) universal sebuah kebudayaan, (5) sifat penelitiannya cenderung kualitatif yang pada akhirnya menghasilkan suatu produk yang sesuai dengan proses yang dialaminya.

\section{TEMUAN \& PEMBAHASAN}

Sebelum pembahasan dan urutan upacara pawintenan Jro Pasek, perlu dibahas tata cara pemilihan Jro Pasek.

Jro Pasek dipilih secara langsung oleh krama desa dari dua desa dinas, yaitu Desa Les dan Desa Penuktukan. Ada enam calon yang ikut bertarung. Pemilihan dilaksanakan pada Manis Galungan, yaitu 8 September 2016. Hasil pemilihan oleh krama lanang, yang menang sebagai Jro Pasek adalah Drs. Med. Vet I Nengah Wiryasa dari dadia Pasek Kayu Selem Kanginan.

Jro Pasek di Desa Pakraman LesPenuktukan merupakan jabatan seumur hidup. Apabila Jro Pasek terdahulu mantuk (meninggal) barulah diadakan pemilihan. Sekadar informasi Jro Pasek terdahulu di winten pada tahun 1965 dan meninggal pada tahun 2015. Selama belum ada pemilihan Jro Pasek yang definitif, ditunjuk salah seorang anggota keraman yang paling senior untuk menjadi seorang Plt. Jro Pasek.

\section{RANGKAIAN UPACARA PAWINTENAN JRO PASEK}

Seperti halnya upacara pewintenan pemangku ataupun pedanda, ada beberapa rangkaian yang harus dijalankan seorang welaka sehingga menjadi seorang Jro Pasek. Pertama, Jro Pasek terpilih, yaitu Drs. Med. Vet I Nengah Wiryasa dan Ni Nyoman Sedani melakukan upacara di rumah Jro Pasek itu sendiri dimulai dari 10 Oktober 2016 yang diawali dengan mebanten di Pura Kemulan Tiga Sakti. Banten yang digunakan sebagai sarana upacara berupa pejati, suci seleean meulam bulu tebel ireng (suci dengan bebek hitam), ketimun nguda (babi guling). Upacara di puput oleh Jro Mangku Maksan Ulun Sari, yang merupakan Jro Mangku Dadia Pasek Kayu Selem Kanginan. Kemudian Jro Mangku ngaturang banten pabersihan sisik tangan sisik siku (pembersihan tangan dan siku). Tujuannya agar kelak tangan dan siku Jro Pasek bersih dari semua kotoran pada saat melaksanakan tugas sebagai seorang pemimpin. Seperti halnya warga di Desa Bali Aga yang lainnya, para pemangku saat ngaturang banten tidak menggunakan mantra berupa Weda, melainkan menggunakan saa (mantra yang diucapkan berdasarkan ingatan, yang telah diwariskan secara turun-temurun oleh para pemangku yang ada di Desa LesPenuktukan).

Terakhir upacara yang dilaksanakan di Sanggah Kemulan Tiga Sakti adalah banten pemutus. Tujuan banten ini adalah untuk memutuskan semua upakara yang telah dipersembahkan kepada Betara Hyang Guru yang berstana di Sanggah Kemulan Tiga Sakti. Kemudian Jro Mangku memercikkan tirta warna solas. Tirta warna solas merupakan tirta pengelukatan yang lazim digunakan untuk warga yang akan mewinten dan nyepuh suci. Adapun bunga yang digunakan sebanyak tiga warna sebagai perlambang Dewa Brahma, Wisnu, dan Iswara. Bunga tersebut terdiri atas bunga merah diwakili oleh bunga tuwi selukat, bunga putih berupa bunga menuri, bunga kuning berupa bunga landep-landepan, bunga hitam berasal dari bunga teleng, dan bunga brumbun berasal dari bunga lainnya, 
seperti bunga cempaka, sandat, kamboja merah putih, bunga kuning lainnya sehingga genap berwarna sebelas.

Setelah maturan di Kemulan Tiga Sakti, lanjut ngaturang piuning di kamar suci. Di kamar suci ini terdapat sebuah kotak kayu yang terdiri atas tiga deret, yang disebut dengan penegtegan. Isi penegtegan ini adalah pis bolong (uang kepeng) sebanyak siu satus (seribu seratus), pitungatus (tujuh ratus), dan satak lima likur (dua ratus dupa puluh lima kepeng). Fungsi penegtegan ini sama dengan isi pedagingan merajan yang ada di wilayah Bali daratan. Banten yang dipersembahkan di kamar suci ini adalah pejati dan banten sodaan.

Lanjut setalah di kamar suci, maturan ke sanggah rerod (sanggah gede), dan sanggah dadia. Banten yang dipersembahkan adalah pejati, suci seleean bulu tebel putih, dan sodaan. Tujuannya adalah untuk meminta restu kepada para leluhur, bahwa sebentar lagi Jro Pasek terpilih akan menjadi pengulu adat.

Siang hari pada 10 Oktober 2016 kira-kira pukul 12.30 Jro Pasek Lanang Istri berjalan kaki menuju Pura Bale Agung yang terletak di utara Desa Les dan berjarak kirakira satu kilometer. Diiringi oleh keluarga besar Jro Pasek (kakak, adik, ipar, dan ponakan) krama Dadia Pasek Kayu Selem. Kemudian di jaba Pura Beji (Kayoan Lanang) disambut oleh para Keraman Pengulu Ulu Likur, kepala desa, warga masyarakat Desa Les-Penuktukan lainnya, diantar naik ke Pelataran Pura Bale Agung. Banten yang dipersembahkan berupa banten pejati, di Kemulan Tiga Sakti Pura Bale Agung, pejati di Penyarikan, di Pemangkalan, dan di candi bentar. Inti ngaturang banten pejati ini adalah sebagai bentuk permakluman kepada Batara Surya, Batara Tiga Sakti, Batara Lempuyang, Ida Batara Barur, dan Ida Batara Puncak Gunung Agung bahwa sebentar lagi akan dilaksanakan pawintenan untuk Jro Pasek baru. Banten yang digunakan hampir sama dengan banten yang dilakukan di Sanggah Kemulan Tiga Sakti, Sanggah Rerod, dan Sanggah Dadia, yaitu pejati, ketimun nguda, dan suci selean bulu tebel putih.

Selama prosesi pawintenan, Jro Pasek Lanang harus melaksanakan mekemit di Bale Suci selama tiga hari. Selama mekemit Jro Pasek terpilih hanya boleh keluar bilik pada pagi hari sebelum matahari terbit untuk mandi dan makan, kemudian pada sore hari (sandi kala). Selama melaksanakan makemit, Jro Pasek dilarang untuk berbicara dengan siapa saja serta melakukan aktivitas apa pun. Tujuan makemit adalah agar dapat mengintrospeksi diri dan kelak setelah menjadi Jro Pasek dapat berbuat yang baik. Selain itu ada, juga kepada anggota masyarakat desa adat.

Rangkaian terakhir dari pawintenan ini adalah upacara mancang karma. Mancang karma dilaksanakan tepat pada hari ketiga, yaitu 12 Oktober 2017 ke Pura Segara Desa Pakraman Les-Penuktukan, yang diikuti oleh seluruh keluarga, warga dadia, serta masyarakat umum. Tujuan mancang karma ini untuk membersihkan diri setelah selama tiga hari mekemit dan melakukan tapa brata. Banten yang dipersembahkan di kemulan tiga, berupa pejati, banten guru piduka, suci putih, soda, serta banten perangkatan.

\section{STRUKTUR ORGANISASI ADAT DESA PAKRAMAN LES-PENUKTUKAN.}

Sebagai salah satu desa Bali Aga, tentunya memiliki banyak perbedaan dengan desa-desa di wilayah Bali Dataran. Salah satu diantaranya adalah struktur organisasi adat. Sebagai sebuah desa Bali Aga, Jro Pasek memiliki kedudukan paling tinggi dalam sistem adat. Jro Pasek berasal dari Desa Les, bukan merupakan jabatan yang bersifat keturunan, melainkan jabatan yang dipilih. Jro Pasek dibantu oleh anggota adat yang lain yang disebut dengan Krama Pengulu Likur. Kraman Pengulu Likur berasal dari dua desa, 
LINGUISTIKA, MARET 2019

p-ISSN: 0854-9613

Vol. 26. No. 1

18 orang dari Desa Les dan 9 orang dari Desa

Penuktukan.

Adapun struktur organisasi adat adalah sebagai berikut.

1. Kedulu Apad terdiri atas.
a. Jro Pasek
b. Jro Kebayan
c. Jro Bau
d. Singgukan
e. Sisik Suku Pat atau Sisik Gede
f. Juru Batek
g. Juru Takeh
h. Penyarikan

2. Nem Aneh termasuk juga Sisik Suku Ro atau Sisik Alit.

3. Paider atau juru wacik

Berikut ilustrasi anggota keraman yang ada di Desa Pakraman Les, Penuktukan. 


\begin{tabular}{|c|c|}
\hline 1 & \\
\hline Kiwe/Kiri & Tengen/Kanan \\
\hline 2 & 2 \\
\hline 3 & 3 \\
\hline 4 & 4 \\
\hline 5 & 5 \\
\hline 6 & 6 \\
\hline 7 & 7 \\
\hline \multicolumn{2}{|c|}{ Kedulu Apad } \\
\hline 8 & 8 \\
\hline 9 & 9 \\
\hline 10 & 10 \\
\hline 11 & 11 \\
\hline 12 & 12 \\
\hline 13 & 13 \\
\hline \multicolumn{2}{|c|}{ Nem Aneh } \\
\hline 14 & 14 \\
\hline \multicolumn{2}{|c|}{ Paider } \\
\hline 15 & 15 \\
\hline
\end{tabular}

Keterangan
1. $\rightarrow$ Jro Pasek
$\mathrm{XX} \rightarrow$ Pemangku Desa
2. $\rightarrow$ Jro Kebayan
3. $\rightarrow$ Jro Bau
4. $\rightarrow$ Jro Singgukan
5. $\rightarrow$ Sisik Gede/Suku Pat
6. $\rightarrow$ Juru Batek
7. $\rightarrow$ Juru Takeh
8. $\rightarrow$ Jro Penyarikan
9. $\rightarrow$ Sisik Alit/Suku Ro
9-14 $\rightarrow$ Nem Aneh.
$15 \rightarrow$ Juru Wacik/Paider

\section{TUGAS DAN KEWAJIBAN KERAMAN}

Setelah memperhatikan struktur organisasi keraman di atas, pada bagian 4 ini dibahas sedikit tentang tugas dan kewajiban seorang keraman, yang ada di Desa Pakrama Les, Penutukan. Adapun tugas dan kewajibannya adalah sebagai berikut.
1. Jro Pasek, seperti yang telah dijelaskan di atas bahwa tugas Jro Pasek adalah sebagai kordinator umum dan sebagai pemimpin seluruh kegiatan yang bersifat adat yang ada di Desa Les, Penuktukan. Selain itu, Jro Pasek juga bertugas untuk mengatur jalannya upacara, memimpin rapat paruman keraman, dan mengatur jalanya roda pemerintahan di desa adat. Pada saat ada warga yang menikah, anggota keluarga tersebut akan menghaturkan jajan, dan banten, sedangkan kalau ada upacara di Pura Bale Agung dan kahyangan tiga lainnya, Jro Pasek akan mendapatkan bagian kepala dari suku pat yang digunakan sebagai sarana banten. Namun, pada saat ada upacara di Pura Bale Agung, Pura Merajan Desa, dan kahyangan tiga lainnya, Jro Pasek harus mengeluarkan jaja kukus ketan dan injin. Namun, beliau bebas dari biaya ayahan adat dan peturunan untuk keperluan upacara dan pembangunan desa.

2. Jro Kebayan bertugas untuk menangani masalah banten yang akan digunakan dalam upacara, mengatur jenis banten yang akan digunakan, mengatur tempat upacara, dan sebagainya. Kewajiban seorang Jro Kebayan adalah mengeluarkan jaja ngina atau jaja begina.

3. Jro Bau bertugas sebagai pembantu umum Jro Kebayan dengan catatan apabila Jro Kebayan meninggal, Jro Bau harus sudah siap mengambil alih semua tugas Jro Kebayan. Jro Bau wajib mengeluarkan jaja suci sebagai sarana upacara.

4. Singguk bertugas untuk mencatat semua bahan yang akan dikeluarkan oleh kerama dan nyama cenik. Nyama cerik adalah istilah untuk seluruh warga adat yang ada di Desa Pakraman Les, Penuktukan, di luar anggota keraman. Kewajiban Singguk adalah mengeluarkan jaja abug, yaitu jajan uli 
yang dibuat dengan ketan dan dicampurkan dengan gula merah (gula Bali).

5. Sisik Suku Pat bertugas untuk mencari semua bahan sajen yang berkaki empat, seperti babi, sapi, dan kerbau. Kewajiban Sisik Suku Pat adalah mengeluarkan jaja abug sama seperti Singguk.

6. Tugas utama Juru Batek adalah memukul kentongan, baik untuk acara upacara, mengadakan rapat, dan kentongan saat akan melaksanakan upacara mekiis. Kewajiban yang harus dikeluarkan saat upacara adalah jajan uli putih.

7. Juru Takeh, tugas utama Juru Takeh adalah menakar bahan upacara, seperti nasi, telur, jajan banten, babi, ayam, sapi, dan yang lain-lain. Kewajiban Juru Takeh adalah mengeluarkan jaja uli putih.

8. Jro Penyarikan, bertugas memutuskan kapan hari baik untuk melaksanakan upacara, mencatat segala keputusan rapat, menentukan kapan warga masyarakat boleh menguburkan keluarga yang meninggal, kapan melaksanakan upacara metuun atau ngaben. Kewajiban yang dikeluarkan untuk keperluan banten upacara adalah tape.

9. Tugas Sisik Suku Ro adalah mencari bahan upacara yang berkaki dua/ro, misalnya ayam, itik, angsa, dan yang lainnya. Yang dikeluarkan saat upacara adalah plepesan, yaitu sejenis jajan yang dibuat dari janur yang berisi tepung dan kelapa lalu direbus. Selain itu, juga berkwajiban untuk membawa pisang dan jaja kukus kuning.

10. Sisa Kelompok Nem Aneh, di luar Sisik Suku Ro, tugasnya mencari janur, daun, kelapa, kelapa muda, rental, pinang, sirih, dan kuud ental atau kelapa muda dari pohon rontal. Karena tugas utamanya banyak, maka yang dikeluarkan pada saat upacara pun dibagi, antara lain dari nomor 10-13 mengeluarkan telur dadar, teri goreng, kecambah matah (mentah), kacang goreng, undis, padi, ketan, injin, dan jagung sebagai bahan untuk membuat penjor. Di pihak lain nomor 14 wajib mengeluarkan janganan atau sayursayuran, seperti terong, pare, papaya, pusuh biu, dan ijuk sambal laos.

11. Juru Wacik, bertugas untuk mencari air, mencuci semua bahan upacara. Pada waktu ngelinggihan gurun desa bertugas untuk mencuci tangan sebelum melaksanakan upacara nyaangang. Yang dikeluarkan pada saat upacara adalah panca pala, yaitu terdiri atas daun andong, daun durian, daun manggis, daun kayu sugih, dan klangsah bungan base. Semua bahan itu digunakan sebagai bahan untuk persiapan banten penyugjug atau semacam banten daksina.

Mengingat tugas dan kewajiban seorang anggota keraman, semua anggota keraman terbebas dari ayahan adat dan ayahan dinas. Selain tugas utamanya sebagai pengayah adat, anggota keraman juga bertugas untuk mewakili desa adat untuk ngaturang atos atau bahan upacara ke Pura Dalem Balingkang, Pura Desa Sukawana, Pura Puncak Panarajon (Pura Pucak Penulisan), Pura Batur, dan Pura Jati Batur.

\section{SIMPULAN}

Sebagai salah satu Desa Bali Aga yang ada di Kabupaten Buleleng, khususnya Desa Pekraman Les, Penuktukan memiliki beberapa keunikan dan ciri khas tersendiri. Salah satu diantaranya adalah sistem organisasi adat yang kemudian dikenal dengan nama keraman Pengulu Ulu Likur. Keraman sendiri terdiri atas 28 anggota, baik laki-laki maupun perempuan. Setiap anggota keraman memiliki fungsi dan tugas masing- 
masing. Anggota keraman bersifat turuntemurun.

Susunan tertinggi dari organisasi keraman adalah Jro Pasek. Jro Pasek sama dengan bendesa adat pada warga di Bali lainnya. Jabatan Jro Pasek bersifat tetap, bukan keturunan. Artinya, kalau Jro Pasek terdahulu meninggal, barulah dipilih Jro Pasek yang baru, bukan keturunan Jro Pasek terdahulu.

Desa Pekraman Les, Penuktukan melaksanakan upacara pawintenan Jro Pasek pada tahun 2016 dan bertepatan dengan Karya Ida Batara Turun Kabeh. Upacara pawintenan ini dilaksanakan mulai dari rumah sendiri dan berlanjut sampai di Pura Bale Agung. Pawintenan berlangsung selama tiga hari, yang ditutup dengan upacara mancang karma.

\section{DAFTAR PUSTAKA}

Bawa, I Wayan dkk. 1983. "Bahasa Bali di Daerah Bali: Sebuah Pemerian Geografi Dialek". Jakarta: Disertasi Fakultas Sastra UI.

Budiastra, I Putu dan I Wayan Wardha. 1989. "Babad Kayu Selem". Denpasar: Museum Bali.

Chaer, Abdul. 2002. Pengantar Semantik Bahasa Indonesia. Jakarta: Rieneka Cipta.

Departemen Pendidikan dan Kebudayaan. 1988. Kamus Besar Bahasa Indonesia. Edisi Pertama. Jakarta: Perum Balai Pustaka.

Hadi, Sutrisno. 1990. Metodologi Research 2. Yogyakarta: Andi Offset.

Kridalaksana, Harimurti. 1992. Kamus Linguistik. Jakarta: PT Gramedia Pustaka Utama.

Leech, Geoffry. 2003. Semantik. Yogyakarta: Pustaka Pelajar

Riana, I Ketut. 2003. "Linguistik Budaya: Kedudukan dan Ranah Pengkajiannya". Pidato Pengukuhan
Jabatan Guru Besar dalam Bidang Ilmu Linguistik Budaya Fakultas Sastra Universitas Udayana. Denpasar: Universitas Udayana.

Riana, I Ketut. 1995. "Masyarakat Gebog Domas di Bali. Studi Tuturan dan Semiotika Sosial". Disertasi. Program Pascasarjana Universitas Airlangga.

Santosa, Riyadi. 2003. Semiotika Sosial, Pandangan terhadap Bahasa. Surabaya: Pustaka Eureka.

Sobur, Alex. 2004. Semiotika Komunikasi. Bandung: Rosda Offset.

Sudaryanto. 2015. Metode dan Aneka Teknik Analisis Bahasa. Yogyakarta: Sanata Dharma University Press.

Sunardi. 2002. Semiotika Negativa. Yogyakarta: Kanal. 